CRÍTICA, Revista Hispanoamericana de Filosofia

Vol. XXIV, No. 70 (abril 1992): 109-132

\title{
STATUS Y VERIFICACIÓN DE LA CREENCIA RELIGIOSA
}

\author{
ALEJANDRO TOMASINI BASSOLS \\ Instituto de Investigaciones Filosóficas
}

UNAM

Desde que en el Teetetes Platón ofreciera y discutiera lo que de hecho se convirtió en la caracterización clásica del conocimiento, la noción de creencia quedó eo ipso envuelta en una bruma de incomprensión de la cual no es sino hasta ahora que empezamos a librarnos. En su importante diálogo, Platón define 'conocimiento' como creencia verdadera acompañada de justificación. Él encuentra que, aunque quizá la mejor de las que se pueden ofrecer, esta caracterización es insatisfactoria por razones que no necesitamos considerar aquí. Lo que aquí nos incumbe es más bien el papel o el status que se le impuso a la creencia y al cual parece haber quedado desde entonces ligada. De acuerdo con la concepción en cuestión, el conocimiento es algo objetivo, público, pero comporta de manera esencial un elemento de adhesión personal. Este elemento es la creencia. Independientemente de su contenido, de su estructura, etc., la creencia en general quedó comprendida como un fenómeno mental, de aprchensión, por parte de un sujeto. La creencia, se nos hizo pensar, es algo esencialmente prelingüístico, o por lo menos lógicamente independiente del lenguaje, y de acceso privilegiado. Yo sé qué es lo que yo creo y otros saben lo que en sus propios casos crcen pero, en relación con las creencias de otros, a lo más que podemos aspirar es a emitir hipótesis y es claro que, dado que no podemos tener un eonocimiento directo 
de las actividades de otras mentes, nunca podremos saber si otras personas creen lo que dicen que creen o, simplemente, nunca podremos determinar con precisión qué creen. Eso es algo que no está en principio a nuestro alcance. Desde esta perspectiva, la creencia se convierte en verdad en un fenómeno extraño. Por otra parte, es importante notar que se apel6 a la noción de creencia para dar cuenta de la de conocimiento y ésta a su vez involucró a la de verdad. De ahí que también "creencia" haya quedado esencialmente conectada con "verdad". Parecería que la clasificación fundamental de las creencias es "verdaderas-falsas". Esto, en caso de ser correcto, tendría decisivas consecuencias para nuestra comprensión de la creencia religiosa.

Es evidente que este cuadro de la creencia contiene serias deficiencias y dificultades. Presupone, por ejemplo, la existencia de un sujeto que tiene las creencias, a quien las creencias pertenecen, convierte a la creencia en algo irremisiblemente incognoscible, entra en conflicto con usos lingüísticos establecidos (decir que uno sabe que conoce sus propias creencias no es decir gran cosa), etc. En el siglo XX, los filosofos del lenguaje ordinario intentaron hacer ver que la dicotomía "verdadera-falsa" no agota todo lo que se puede decir respecto a la creencia. En particular, ellos llamaron la atención sobre la distinción, en principio relevante para la filosofía de la religión, "creer que-creer en". Las expresiones de la forma 'creo que', se nos asegura, tienen una logica distinta de la de las expresiones de la forma 'creo en'. 'Creer que' significa, fundamentalmente, que una mente (concíbasela como se la conciba) mantiene una relación cognoscitiva con una proposición, en tanto que 'creer en' indica más bien una relación sentimental con un objeto (en un sentido amplio). Esta distinción la trazaron ellos, en parte por lo menos, con ánimo de ofrecer una caracterización no mentalista de la creencia y de poner en su lugar una concepción conductista de la creencia. Así, diríamos que $A$ cree que $P$ porque, e.g., está dispuesto a emitir $P$ en tales o cuales 
circunstancias, a asentir si otros aseveran que $P$, ete. $\mathrm{Y}$, por otra parte, diríamos que $A$ cree en $B$ si $A$ tiene una conducta favorable, de modo general, hacia o por $B$.

Aunque sin duda alguna esta distinción puede echar luz sobre ciertos rasgos de las creencias, en lo fundamental a mí me parece puramente verbal y, por consiguiente, de poca monta. De hecho, todo lo que se diga de un modo se puede decir del otro. Por ejemplo, si digo que creo en el socialismo, lo que digo es inter alia que creo que el socialismo es el mejor sistema de los que hasta ahora se han materializado, que el progreso social transita por la vía del socialismo, etc. De ahí que la situación parezca más bien ser la siguiente: se emplea "creo en" para poner sobre aviso al escucha de que hay una serie indeterminada de proposiciones que el hablante acepta. "Creer en" es más bien un mecanismo de economía del lenguaje. Pero el reconocimiento de este hecho por sí mismo no nos sirve mayormente para la comprensión de la creencia religiosa, para la aprehensión de su especificidad. No avanzo en nada por la senda de la comprensión si se me informa que cuando digo que creo en Dios estoy comprometiéndome con o implicando (incluso tal vez en un sentido fuerte de 'implicación') proposiciones como 'Creo que Dios existe', 'Creo que todo aquel que niegue que Dios existe está equivocado o se contradice', etc. Además, la distinción se aplica de igual modo a las creencias religiosas que a las políticas, a las científicas (aunque es un tanto inusual emplear 'creo en' en ciencia. Pero no es ilegítimo), etc. Qué sea la creencia religiosa es, por lo tanto, algo en relación con lo cual los análisis usuales esclarecen poco.

Es con Ludwig Wittgenstein que, en éste como en muchos otros dominios de la filosofía, se logró efectuar un progreso real. Gracias a la articulación de un reducido número de conceptos "teóricos" (espero que no se me malinterprete: no estoy afirmando que Wittgenstein ofrece teorías), Wittgenstein puede ofrecer descripciones detalladas de problemáticas filosóficas de modo tal que la dificultad se desvanece. Para nuestros pro- 
pósitos hay que servirse únicamente de dos de sus nociones técnicas, a saber:

1) criterios, $y$

2) semejanzas de familia.

Me parece evidente que ningún esfuerzo por esclarecer la naturaleza de la creencia religiosa puede iniciarse con el tratamiento de casos raros, límite, problema, etc., sino que, al contrario, tiene que iniciarse con el de casos paradigmáticos. A los niños, por ejemplo, se les enseña a usar el término 'creer' y sus asociados (como 'creencia') de algún modo, por lo que es muy probable que las consideraciones de situaciones ejemplares de enseñanza puedan ayudarnos a comprender la significación de los términos y, por ende, puedan ayudarnos a aprehender cl concepto que nos interesa.

Supongamos que un niño busca una pelota cn el jardín y que la pelota que él busca está en su cuarto. Nosotros, después de su infructuosa búsqueda, le decimos: 'Tú creíste (o creías) que la pelota estaba en el jardín, pero nunca la ibas a cncontrar allí porque estaba en tu cuarto'; jugamos a las escondidas con un niño y lo "encontramos". Le decimos entonces: 'Creíste que no te encontraría, pero... '; el niño no hace la tarea y lo castigan en la escuela. Comentamos: 'Creíste que la maestra no cumpliría lo que dijo, pero ya ves que te equivocaste'. Los ejemplos se pueden generar indefinidamente. En general, sin embargo, parecería que empleamos 'creer' en una multitud dc situaciones y, muy a menudo, para describir o explicar nuestra previa falıa de conocimiento. Se trata de un recurso lingüístico para descubrir una conducta de cierto tipo (en nuestros ejemplos, conducta contextualizada no exitosa). Es sólo después, i.e., una vez quc este uso de 'creer' ha sido asimilado, que podemos afirmar cosas como 'Él creía que $F$ y creía bien (porque ' $P$ ' es verdadero). De hecho, entonces, en su uso primario, 'creer' se contrapone a 'conocer', sobre todo si se emplea en pasado o en copretérito. Si se emplea en presente estas connotaciones negativas desapa- 
recen, puesto que se está todavía, por así decirlo, en suspenso. De ahí que si yo digo 'Yo también creí en Dios', de hecho esté implicando que ahora creo que estaba en un error. El punto central, sin embargo, es que 'creer' y derivados sirven para caracterizar de modo abstracto una conducta supuestamente racional (no necesariamente exitosa), a menudo verbalizada y contextualizada. Una mosca ni cree ni no cree nada, es decir, el concepto de creer no se le aplica. Es conveniente notar que hay una transición gradual desde los casos paradigmáticos (en los cuales están presentes múltiples factores con base en los cuales podemos aplicar un determinado término psicológico) hasta los casos en los que la presencia de tan sólo uno o algunos de los factores originales basta(n) para que prediquemos algo de alguien (e.g., que tiene una creencia). Los "factores" en cuestión, que no son otra cosa que la situación objetiva y las acciones del sujeto en ella inmerso, son lo que Wittgenstein llamó 'criterios'. Es porque disponemos de criterios que podemos atribuir significativamente creencias a alguien.

Intentemos ahora destacar la importancia para nuestro asunto de la noción de semejanzas de familia. Es evidente que nuestras creencias pueden ser de lo más variado: podemos tener creencias acerca de la luna, de los ratones, del amor o de los triángulos. En ocasiones expresamos nuestras creencias, pero no tiene ello por qué ser así. Es más: hay creencias con las que estamos lógicamente comprometidos y de las cuales no estamos conscientes. A veces, en el momento en que damos expresión a nuestras creencias tenemos imágenes mentales determinadas o incluso, podría concederse, sensaciones particulares. Pero esto no siempre es el caso. Más aún: aunque lo fuera, la aparición de imágenes en la mente de alguien es irrelevante para la atribución de creencias. El concepto de creencia no depende del de imagen mental. Difícilmente podría negarse, por ejemplo, que si se le preguntara a las personas qué imágenes tienen o qué sienten cuando (verazmente) afirman que creen algo, la gran mayoría de ellas no sabría qué decir. En vano, pues, se 
buscaría en los diversos contextos o en las variadas líneas de conducta de las personas un elemento que estuviera presente en todas las creencias. Lo que nosotros llamamos 'creencias' constituyen un conglomerado que no qucda conformado por uno o varios elementos comunes. (Por eso la búsqueda de definiciones es aquí una tarea fútil.) Una vez más, hay casos paradigmáticos y una transición gradual en diversas direcciones. Es por eso que puede decirse que las creencias se asemejan entre sí como los miembros de una familia.

Me parece que ahora sí ya estamos en posición de preguntar qué clase de creencia es la creencia religiosa. ¿En qué se distingue o cómo se caracteriza una creencia religiosa? (Aquí evito formular la pregunta en los términos en los que ya ha sido formulada en diversas ocasiones, viz., '¿Qué hace religiosa a una creencia?', por la sencilla y obvia razón de que esta pregunta presupone lo que acabo de negar, viz., que hay tal cosa como la esencia de la creencia, además de particularidades, como la de ser religiosa.) Preguntémonos más bien: ¿Cuándo decimos de alguien que tiene una creencia religiosa? Y es sólo después de que se haya logrado determinar que alguien tiene una creencia religiosa que podremos enfrentarnos al problema de determinar cómo se le valida.

Yo pienso que los dos criterios fundamentales que nos autorizan a aseverar que una persona mantiene creencias religiosas son lenguaje y praxis y de ellos dos el decisivo es, en última instancia, la praxis. De la interacción de la praxis y la expresión verbal surgen los "estados mentales religiosos": ciertas actitudes, ciertas emociones, sentimientos, etc. Y, de nuevo, hablar de sentimientos, emociones, etc., religiosos no es remitirnos al reino de lo incognoscible salvo para el sujeto, puesto que en general tenemos criterios para aplicar a otros el lenguaje psicológico en todas sus variantes. Esto me parece relativamente claro. Lo que resulta más problemático es la cuestión de si para la gestación de la vida religiosa son indispensables institucio- 
nes religiosas (iglesias, ritos, credos, etc.). Sobre esto diré algo rápidamente más abajo.

No hay tal cosa como una "creencia" que no tiene ninguna clase de manifestación. Esto, empero, no es un descubrimiento empírico, sino una mera constatación gramatical: 'creencia' no es aplicable fuera de un contexto que dota de significación u orientación a las acciones del sujeto que tiene la creencia, si no hay manifestaciones lingüísticas, etc. Esto, por otra parte, no borra las asimetrías entre la primera y la tercera persona ('yo creo' y 'él cree'). Difícilmente se podría, e.g., atribuir a alguien la creencia en la superioridad de su raza o su pueblo si trata a todos los seres humanos por igual, es amable con todos, se manifiesta en contra de toda clase de racismos, etc. En el caso de la primera persona, es obvio que puede haber procesos introspectivos para determinar o descubrir qué es lo que de hecho uno cree, pero, primero, eso parece ser un fenómeno más bien raro (sólo en muy excepcionales circunstancias se vuelca uno sobre sí mismo con el fin de descubrir qué creencias se tiene) y, segundo, presupone el uso del lenguaje porque ¿cómo podría yo saber que creo que $P$ si no me digo yo a mí mismo que ' $P$ ' es verdadero? $Y$ es claro que decir algo (a uno mismo, en soliloquio interno o en diálogo con otros) es o la expresión de autoadscripción de una creencia o un criterio para la atribución a otros de creencias. Por otra parte, si ni en mi caso ni en el de otros se producen acciones o actos religiosos, entonces aunque digamos que tenemos creencias religiosas o que otros las tienen, las creencias en cuestión no pasan de ser un mero asentimiento verbal a una proposición. De ahí que lo que convierte a una creencia en religiosa proceda no tanto de particularidades intrínsecas a ella, sino fundamentalmente de elementos "externos" a ella, como la praxis religiosa (i.e., las acciones significativas religiosamente, para lo cual son indispensables un contexto, un lenguaje, etc.). En otras palabras, la determinación de una creencia como religiosa presupone que se ha aclarado ya la naturaleza del lenguaje religioso y la de 
los actos religiosos. ‘¿Qué es una creencia religiosa?’ es, por lo tanto, algo que puede responderse diciendo que es la creencia expresada en un lenguaje religioso y que ha cobrado forma a través de acciones religiosas. Se trata, por lo tanto, de una pregunta lógicamente secundaria o derivada o, también, de una pregunta cuya respuesta depende de otras.

Nuestro problema original se ha, pues, transmutado, y es ahora el de determinar la naturaleza del lenguaje religioso y de lo que serían acciones típicamente religiosas. No me propongo adentrarme aquí en estas cuestiones y me limitaré a enunciar la línea de explicación que me parece la adecuada, esto es, la auténticamente aclaratoria. Primero, en lo que al lenguaje natural atañe: es el lenguaje natural usado de un modo peculiar, especial. No es un lenguaje "teórico" o "técnico". Como Wittgenstein nos enseñ6, el uso de imágenes es en él imprescindible. Segundo, un acto religioso es un acto descriptible o realizable únicamente por medio del lenguaje religioso y que está asociado con emociones y sentimientos rcligiosos. De todo esto parece desprenderse algo sumamente importante, a saber, que "lo religioso" (lenguaje, sentimientos, acciones, instituciones, etc.) constituye o conforma un dominio que no tiene explicación más que en términos de sí mismo. En otras palabras, "lo religioso" constituye o es una forma de vida.

Aunque, sin duda alguna, hay muchos interrogantes no respondidos en lo que acabo de decir acerca de la crecncia rcligiosa, espero haber echado alguna luz sobre el tema, en particular sobre el carácter derivado del asunto. Quisiera ahora pasar a considerar la segunda cuestión mencionada en el título del trabajo, es decir, la de si existe algún modo peculiar para vcrificar, en algún sentido, una creencia religiosa. Naturalmente, lo que tenga que decir a este respecto deberá scr acorde con la respuesta ofrecida en relación con el primer punto. Nhora bien, para este segundo tema la formulación adecuada del problema y la respuesta que deseo esbozar 
aquí requieren, a manera de recordatorio, de un par de palabras.

La noción de verificación fue puesta en el centro de la discusión filosófica reciente por los empiristas lógicos. Como es ya bien sabido, ellos nunca pudieron ofrecer una formulación adecuada de su famoso principio de verificación, lo cual no dejaba de ser grave para su programa. Se suponía que era el principio en cuestión lo que permitiría deslindar con toda precisión entre clases de enunciados (creencias, proposiciones) y determinar así a qué grupo pertenece un elemento dado. Grosso modo, los grupos podían ser los constituidos por:

a) tautologías

b) enunciados significativos (i.e., con contenido empírico, con valores de verdad, etc.)

c) pseudoenunciados (sinsentidos).

Lo que el criterio empirista permitía era, dejándonos con la conciencia tranquila, ubicar en el grupo de los pseudoenunciados a todas las afirmaciones de la metafísica, la ética, la estética, etc., y, obviamente, a las de la religión (incluyendo la teología). El núcleo de la tesis era bastante simple: lo que se sostenía era sencillamente que las afirmaciones del grupo c) no tenían contenido empírico, o sea, no eran afirmaciones acerca de la realidad. Su función era otra.

Yo creo que aunque hay que reconocer que los empiristas efectivamente fracasaron en sus esfuerzos por encontrar un criterio formal que les habría permitido deslindar lo significativo de lo sin sentido, no por ello su intuición es errada. Su error fue no el de señalar e insistir en que alguna diferencia fundamental debe existir entre, e.g., una afirmación de la mecánica y una de un texto sagrado, sino en reconocer y asignarle al lenguaje tan sólo un par de funciones (descripción-expresión de emociones) y luego buscar un principio de sencilla formulación que diera cuenta de dicha distinción (asumida a priori). La gran ventaja 
de poseer un principio así consistiría en que habría convertido todo el trabajo en filosofía en un trabajo puramente mecánico, pues éste se reduciría entonces a aplicar el principio a casos problemáticos de enunciados. Ahora bien, aunque es cierto que las cosas no son tan sencillas como los empiristas lógicos supusieron, también lo es que resulta muy difícil (por no decir imposible) no sentir la fuerza (y el atractivo) de su intuición motriz. A ésta habremos de tenerla presente.

Es claro que el problema de la verificación efectiva o de principio de nuestras afirmaciones es de crucial importancia para religiosos, teólogos, filósofos de la religión, religionistas, etc., puesto que, en su gran mayoría, ellos pretenden hacer del discurso religioso un discurso cuya verdad puede ser establecida de modo racional. Su supuesto decisivo y no discutido es el de que las afirmaciones teístas pueden ser entendidas literalmente: que si se dice que habrá un Juicio Final se está eo ipso afirmando que, en algún sector del espacio-ticmpo, se producirá un fenómeno especial al que llamamos 'Juicio Final', que si se dice que alguien le ordenó a un muerto salir de la tumba y caminar, éste realmente hizo eso, etc. Parecería, por lo tanto, que si se desprovee al teísmo de sus pretensiones de verdad, éste sencillamente se derrumba. Pero isignifica el derrumbe del teísmo la destrucción de la religión? ¿No hay acaso otros modos de entender el lenguaje religioso que el modo teísta de hacerlo? Es porque coadyuva a la resolución de esta decisiva cuestión el asunto de la verificación de las afirmaciones religiosas que éste reviste una gran importancia.

Dados los conflictos con lo que parece ser una intuición básicamente sana, esto es, la de los empiristas lógicos, los partidarios del teísmo han optado por elaborar y dcfender nuevas vcrsiones de vcrificación o de verificabilidad. Una de ellas, la más audaz quizá, es la desarrollada sobre todo por el gran filósofo de la religión, J. Hick. Me refiero a la interesante noción dc verificación escatológica. En este trabajo me propongo reconstruir, discutir y trabajar en torno a la argumentación de 
Hick. Para los efectos de la exposicion y de la discusión, tal vez lo mejor sea dar a conocer desde ahora mi punto de vista: yo pienso que, a pesar de que la teoría de Hick pone de relieve un gran ingenio, de todos modos el esfuerzo es fallido. Pero veamos rápidamente en qué desemboca dicho esfuerzo.

La estrategia de Hick es la siguiente: se trata de mostrar que afirmaciones como 'Dios existe' son portadoras de valores de verdad y, a fortiori, son perfectamente inteligibles. Dichas afirmaciones tienen un contenido factual, al igual que cualquier oración del lenguaje natural o, según suponen algunos, de la ciencia natural. Hick propone entonces que entendamos por 'verificación' simplemente la eliminación racional de dudas respecto al valor de verdad de una proposición dada. Por otra parte, es siempre alguien quien verifica algo. Luego la faceta del proceso de verificación que más nos interesa es la eliminación de dudas respecto a la verdad en una mente individual o particular. "La 'verificación' es, pues, en primer lugar el nombre de un evento que tiene lugar en la conciencia humana." Hick señala acertadamente que la verificación está asociada con una enunciación condicional de situaciones. Sea la tesis $\phi$. Entonces decir que $\phi$ ha sido verificada es decir que $s i$ se dan tales y cuales condiciones, entonces se produce lo enunciado en $\phi$. Esto es obvio, pero Hick establece un punto que ya no lo es tanto. De acuerdo con él, cómo se verifiquen las condiciones es algo que dependerá de la clase de objetos de que se trate. "Desde luego que el contenido de las cláusulas 'si' está siempre determinado por el tema particular."2 $\mathrm{O}$ sea, ciertos requisitos se tienen que satisfacer para verificar afirmaciones acerca de estados mentales, otros requisitos serán los apropiados para verificar afirmaciones acerca de números, otros para

1 J. Hick, "Theology and Verification" en B. Mitchell (comp.), The Philosophy of Religion, Oxford University Press, 1971 (Oxford Readings in Philosophy), p. 54.

2 Ibid., p. 56. 
enunciados sobre objetos materiales, etc. y, naturalmente, otros serán los requisitos para afirmaciones acerca de la divinidad. Sería absurdo pretender uniformar las condiciones iniciales. En palabras de Hick, "la lógica de 'Dios' determina lo que se tiene que hacer para verificar enunciados acerca de Dios". ${ }^{3}$ Con esta caracterización global de la noción de verificación, Hick pasa a enunciar su tesis de la verificación escatológica.

Yo creo que lo más importante para nosotros es tener una idea clara del itinerario argumentativo de Hick. Éste no rechaza que toda creencia con contenido tenga que poder ser verificada de algún modo. Más bien, a lo que él aspira es a darnos la peculiar "lógica" de la verificabilidad en el caso de la afirmación 'Dios existe'. Él, además, trata no sólo de verificar la proposición en cuestión, sino de confirmar ciertas doctrinas específicamente cristianas. A Hick no le interesa defender una teoría de la inmortalidad que resultara natural desde un punto de vista religioso. Cualquier filósofo pagano podría hacer eso. Lo que a Hick le importa es más bien desarrollar lo que podríamos llamar una 'metempsicosis católica'. El defiende, con argumentos dignos de ser considerados, la doctrina pablista de la reencarnación. De acuerdo con ésta, la corrupción del cuerpo no sólo no implica la corrupción del alma, sino que la resurrección no es (o no tiene por qué ser) idéntica a la reconstitución del cuerpo. Así, pues, de acuerdo con su exégesis no sería lógicamente imposible que se constituyera un cuerpo que posea todas las características que tenía el cuerpo original antes de que se descompusiera, al tiempo que (aunque numéricamente distintos) aceptáramos que se sigue tratando de uno y el mismo cuerpo. Nuestras almas podrían reencarnar en una réplica (soma pneumatikon) de nuestro antiguo cuerpo, del cual empero tendríamos que decir que es el mismo que el que teníamos antes de morir. El argumento de Hick en favor de la posibilidad logica de su tesis de la reencarnación queda introducido

3 Ibid., p. 56. 
por medio de un singular ejemplo, que es el siguiente. Pensemos en un ser querido con quien platicamos una mañana. Súbitamente esta persona desaparece y aparece en, digamos, Australia. Nos desplazamos hasta allá y nos encontramos con lo que parece ser a todas luces la misma persona. No tenemos la menor idea de cómo pasó de un lugar a otro, pero cuando la examinamos, la interrogamos, etc., todo concuerda: no tenemos más remedio que reconocer que se trata de la misma persona que estaba con nosotros y que misteriosamente desapareció. Pero la mera desaparición misteriosa no podría ser un argumento en contra de su identidad. Hick va incluso más allá y nos propone que la persona en cuestión muere, pero que, una vez más en Australia, aparece su réplica. De nuevo se le hace pasar todos los tests que se nos puedan ocurrir (recuerdos de infancia, proyectos comunes que se tenían, identificación sin problemas de familiares y amigos, etc.) y los pasa exitosamente. Hick sostiene que aunque la hipótesis sea inverosímil, es lógicamente posible. Pero si es lógicamente posible, entonces es perfectamente comprensible que sea en mi réplica en la que reencarne mi alma y que dicha réplica se encuentre no en Australia sino en otro mundo, después de que yo haya muerto. La tesis, insiste Hick, no sólo no es contradictoria en sí misma, sino que es perfectamente comprensible. Ahora bien, como ya dije, la mera resurrección, por extraña que sea, no apoya en nada la existencia de Dios. Después de todo, podría tratarse de un 'hecho natural sorprendente', como bien dice Hick. Pero entonces icómo se establece la conexión entre la resurrección y la creencia en Dios? Hick piensa que se pueden dar argumentos en favor de la idea de que hay una situación que claramente sugiere o apunta a la existencia de un Dios de amor. Él sostiene que nuestra experiencia puede desarrollarse de dos modos distintos, de tal manera que pudieran eliminarse las dudas que racionalmente se pudieran tener respecto a la existencia de un Dios benévolo (padre, etc.), sobre la base de que la doctrina de la reencarnación es lógicamente posible. 
“Éstas son, primero, una experiencia de la realización de los propósitos de Dios para con nosotros [...] y, segundo, [ello] en conjunción con la experiencia de comunión con Dios, tal como se nos revela en la persona de Cristo." ${ }^{4}$ Es claro que si se goza de esta experiencia y se acepta la doctrina de la reencarnación, entonces sí podemos confirmar (verificar) la proposición 'Dios existe'. Ahora bien ¿̇cuál es esta experiencia? En este punto, me parece pertinente cederle la palabra a Hick. Según él:

El propósito divino para la vida humana [...] es el de llevar a la persona humana, en sociedad con sus semcjantes, a disfrutar cierta cualidad valiosa de vida personal, cuyo contenido está dado en el carácter de Cristo - de cuya calidad de vida se dice que es el destino propio de la naturaleza humana y la fuente de la realización propia y la felicidad últimas. La situación de verificación con respecto a dicha realización es asimétrica. Por una parte, en la medida en que el propósito divino no es satisfecho, no podemos saber que será satisfecho en el futuro; de ahí que no sea posible ninguna falsificación final de la tesis de que esta satisfacción ocurrirá - a menos, desde luego, que la predicción contenga una cláusula específica de tiempo, que la enseñanza cristiana no contiene. Pero por otra parte, si el propósito divino es satisfecho, entonces cuando lo sea podrcmos reconocerlo y alegrarnos en esa realización. Porque la realización no sería para nosotros la realización prometida sin nuestra propia participación consciente en ella. ${ }^{5}$

Obviamente, la otra condición para dejar establecido de modo definitivo el teísmo cristiano (sobre la base de que la verificación escatológica es posible) es que "la realización del propósito de Dios sea aprehendida como la realización del propósito de Dios, y no simplemente como un estado de cosas natural."6 De las dificultades que engendra la cuestión del reconocimiento de Dios (por definición inobservable, intocable,

4 lbid., p. 67.

5 lbid., p. 67.

6 Ibid., pp. 67-68. 
etc. y provisto de propiedades incomprensibles para la mente humana) lo saca la teología cristiana. Dios es Cristo y, por consiguiente, puede afirmarse que "Es la unión de Dios con el hombre en Cristo lo que hace posible el reconocimiento por parte del hombre de la realización del propósito de Dios para el hombre como siendo en verdad la realización del propósito de Dios para él."7 De este modo, Hick cree poder dejar establecida su tesis central. No obstante, su tesis de que la doctrina de la reencarnación verifica al teísmo cristiano depende, naturalmente, "de que el cristiano tenga un contacto genuino con la persona de Cristo, incluso aunque éste esté mediado a través de la vida y la tradición de la Iglesia".

La exposición de Hick parece girar en torno a la plausibilidad del ejemplo por él construido. Yo soy de la opinión de que si se considera que el ejemplo es aceptable, entonces Hick tiene argumentos fuertes para defender su tesis, pero aparte de que hay razones para pensar que el ejemplo no es lógicamente coherente, todo el razonamiento de Hick parece estar inmerso en serios enredos. En mi opinión, podemos elevar en contra de Hick por lo menos las siguientes objeciones:

1) La idea acertada de Hick de que la verificación es siempre efectuada por alguien lo lleva, curiosamente, a incurrir en una falacia: del hecho de que siempre haya alguien (es decir, por lo menos alguien) que verifica algo no se sigue que pueda haber verificación en el caso en que sólo alguien (i.e., a lo sumo alguien) pueda efectuar la verificación. Esto, que es lo que Hick dice, equivale a una deformación de nuestro concepto de verificación porque ¿qué podría ser una verificación privada? ¿No podría equivocarse quien supuestamente verifica? Y si se equivoca ¿cómo podría detectar su error? A estas y otras preguntas le sería muy difícil responder a Hick.

7 Ibid., p. 69.

${ }^{8}$ Ibid., pp. 69-70. 
2) Toda la argumentación de Hick parece fundarse en un rechazo implícito de un principio filosófico fundamental, a saber, el Principio de Identidad de los Indiscernibles. En efecto, lo que Hick sostiene es que puede haber dos cuerpos que comparten todas sus propiedades, esto es, son idénticos (uno es una réplica del otro) y que, no obstante, difieren solo numero. Sin argumentos fuertes en contra del principio mencionado la exposición de Hick ni siquiera tiene sentido.

3) Es claro que el ejemplo de Hick comporta alteraciones drásticas en nuestro aparato conceptual. En particular, el concepto de objeto se ve seriamente afectado. Un objeto es para nosotros, aquí y ahora, algo espacial, temporal, que mantiene relaciones causales con otras entidades, que es coloreado, que está sometido a leyes (no desaparece súbitamente, etc.). Siempre que empleamos la palabra 'objeto' estamos automáticamente arrastrando sus rasgos esenciales. Siendo esto así ¿de qué puede estar hablando Hick cuando enuncia su ejemplo? ¿Cómo podría haber un objeto que desaparece aquí y de pronto aparece a $8000 \mathrm{~km}$ de distancia? La pregunta, naturalmente, no apunta a complicaciones físicas, sino de comprensión: ¿es conceptualmente posible que haya un cuerpo (y por ende una persona) como el que Hick describe, incluso si admitimos que es lógicamente posible? La respuesta es, creo, que no, pero entonces su ejemplo se derrumba.

4) Toda la argumentación de Hick tiene como objeto encontrar razones para fundamentar (verificar) la creencia en la existencia de Dios, pero sin el recurso a la teología cristiana su argumento no progresa. Luego la argumentación de Hick tiene todas las apariencias de la argumentación circular.

5) Aunque no decisiva, me parece también digna de ser tomada en cuenta la siguiente objeción: psicológicamente la situación que Hick plantea no tendría las consecuencias que él espera. De seguro que la relación sentimental que podría surgir con una réplica de un ser querido no sería idéntica a la que mantenemos con el original. Lo más probable es que siempre 
nos acompañara el pensamiento: "A quien yo realmente quería era a la otra persona. Esto de todos modos sigue siendo un fraude." Y ¿nos puede asegurar Hick que no sucedería lo mismo en nuestro propio caso, una vez reencarnados? ¿No podría darse el caso de que dijéramos, e.g., "Me acuerdo cuando era de carne y hueso. Me sentía más a gusto"? Pero entonces ¿qué clase de reencarnación es ésa?

Las dificultades que aquí hemos señalado en relación con el texto de John Hick surgen porque éste de hecho acepta la intuición de los empiristas de que si se habla genuinamente del mundo debe haber algún modo de verificar si lo que se dice o cree es como se dice o cree. Hick trata de hacer ver que cualquier empirista flexible debería aceptar también que por lo menos en principio es legítimo hablar de verificación en el caso de las creencias religiosas, aunque se trataría de procesos de verificación un tanto especiales. He tratado de mostrar que el esfuerzo de Hick es fallido, pero quisiera ir adelante y tratar de dar un diagnóstico del mal. Desde mi perspectiva, el mal que aqueja a propuestas como la de Hick es que en todas ellas se presupone que el lenguaje sólo puede servir para describir hechos (físicos, mentales, religiosos, estéticos, etc.). Éste me parece a mí que es el error fundamental. En lo que sigue intentaré esbozar una línea de respuesta a lo que es el problema central de este trabajo y que podríamos formular así: si rechazamos que haya tal cosa como aseveraciones religiosas, es decir, si rechazamos que el lenguaje religioso tiene contenido factual ¿cómo entonces se verifica una creencia religiosa?

Se recordará que he estado insistiendo en dos puntos especialmente:

1) la creencia religiosa es como creencias de otras clases, pero ticne sus características propias, y

2) la intuición empirista acerca de la significatividad es prima facie válida. 
De esto parece seguirse que tenemos que descartar de entrada el procedimiento fácil que consiste en traspasar al terreno de las creencias religiosas las pruebas, los tests, los criterios, etc., que se aplican normalmente a otras clases de creencias. Frente a esto, creo que lo que es verdaderamente crucial en el caso de las creencias religiosas es percatarse de que no es la verdad o la falsedad (en el sentido de, e.g., la teoría de la verdad como correspondencia) lo que está en juego. No es un hecho especial lo que confirma o refuta a una creencia religiosa. Si es un hecho lo que confirma una creencia, entonces automáticamente la creencia en cuestión tiene contenido factual, versa acerca del mundo, por misterioso o raro que pueda ser el fenómeno en cuestión. Pero la religión no se ocupa de hechos, no es una superbiología o una superfísica, ni tiene por qué entrar en conflicto con las ciencias naturales. Siendo esto así ¿qué significado le podemos atribuir a la expresión 'verificación de una creencia religiosa'? ¿Hay tal cosa o no?

A mí me parece que, dejando de lado cuestiones meramente lingüísticas, hay un sentido especial en que podemos emplear, en relación con la creencia religiosa, a la familia entera de nociones relacionadas con la de verificación (comprobación, refutación, confirmación, etc.). De seguro que hay un sentido de acuerdo con el cual una creencia religiosa se corrobora (puesto que las creencias religiosas no son arbitrarias), sólo que este sentido es diferente del sentido según el cual se corrobora una hipótesis científica, por ejemplo. La diferencia procede del hecho de que en un caso una creencia tiene contenido factual y en otro no. ¿Cómo se corrobora o refuta una creencia factual? De muy diverso modo. Por ejemplo, se emiten hipótesis deducibles de ella y que son empíricamente confirmables. Si éstas se producen, entonces la creencia está confirmada; de lo contrario queda refutada; o bien, dado que no podemos verificar directamente todo (por ejemplo, no podemos verificar o confirmar personalmente afirmaciones como la de que dentro de diez millones de años ya no habrá nadie sobre la Tierra), por 
lo menos podemos integrar esa afirmación dentro del corpus de nuestras creencias y podemos dar razones en favor o en contra de ella. $\mathrm{O}$ sea, por lo menos en principio sabcmos qué tendría que pasar para que un enunciado como el del ejemplo quedara verificado o refutado. Por razones que ya serán obvias, no es de estos procedimientos que hablamos cuando hablamos de verificación de creencias religiosas, puesto que en estos casos no hay hechos que las confirmen o desconfirmen. Nuestro problema, por lo tanto, es determinar qué queremos decir cuando hablamos de la verificación de una creencia religiosa, asumiendo que la expresión 'verificación de creencias religiosas' no es un sinsentido.

Una creencia religiosa no es una creencia relativa a un estado particular del mundo o a un periodo particular de nuestra existencia, sino que tiene que ver, de uno u otro modo, con el todo de nuestra vida. Una creencia religiosa genuina nos acompaña permanentemente. Ahora bien, la creencia religiosa se expresa necesariamente por medio del lenguaje religioso y su importancia se mide por su impacto en nuestras vidas, esto es, en la conducta que sea susceptible de generar. De ahí que podamos sostener que la verificación de una creencia religiosa es una función de las posibilidades de acción abiertas al sujeto por el lenguaje religioso de que se trate. Así, los valores de verdad son a las creencias factuales lo que el éxito o el fracaso en la promoción de un determinado modo de vida (a saber, el religioso) son a las creencias religiosas. Una creencia religiosa se confirma cuando obliga al sujeto a vivir de cierto modo (hablo, naturalmente, de constricción aceptada, si bien son indispensables métodos para inculcar las creencias religiosas de que se trate), así como una ley científica se confirma cuando permite hacer predicciones que la verifican. A diferencia de la verificación que se lleva al cabo en, digamos, las ciencias empíricas, la verificación de las creencias religiosas es fundamentalmente de orden personal: es el sujeto que tiene las crcencias quien confirma o desmiente su validez, quien las verifica o refuta. 
Una religión queda refutada al no ser seguida, al no dar pie a ninguna práctica, lo cual obviamente no es el caso de las creencias científicas (se supone que las leyes de la naturaleza son independientes de que las conozcamos y enunciemos o no). La verificación en el caso de las creencias religiosas es un asunto de aceptación, no de contrastación con la realidad. Esto nos permite exhibir otra característica de las creencias religiosas, que me parece digna de ser tomada en cuenta: el sistema de creencias religiosas tiene su racionalidad interna, sus criterios propios de verificación y refutación, o aceptación y rechazo. No tiene entonces el menor sentido aplicarle otros criterios de racionalidad, como por ejemplo los que operan en la investigación científica. Pero si esto que digo es acertado, entonces sí puede afirmarse con confianza que el teísmo es el resultado de una serie de incomprensiones del fenómeno religioso (creencias, lenguaje, vivencias, etc.) y que la visión adecuada de la religión está todavía por construirse.

Un problema que surge en este punto es el siguiente: si los procesos racionales de verificación (con todo lo que implican) son ajenos por completo a la creencia religiosa $i$ No corremos el riesgo de convertir a la creencia religiosa en algo totalmente irracional? ¿Qué diferencia habría entre una creencia religiosa (digamos en un castigo eterno) y un cuento de hadas o uno de horror? Dicho de otro modo: ¿No está acaso implicado en lo que estoy sugiriendo que la creencia religiosa es algo completamente irracional? Yo pienso que no, pero es evidente que la dificultad merece algunas consideraciones.

A primera vista es inevitable, si se abandona toda clase de cientificismo en religión, no sentir la tentación de aceptar una posición completamente opuesta. Quizá no sea errado afirmar que la posición opuesta al cientificismo o al racionalismo sea el fideísmo. Caracterizado por contraste, lo que este último enfatiza son cosas como la voluntad de creer, el elemento de adhesión personal, la aceptación de "verdades religiosas" sin someterlas a ninguna clase de examen crítico, racional, etc. En otras 
palabras, parecería que puesto que hemos abandonado la vía de la demostración, de la verificación (en el sentido científico de la expresión), etc., para nuestras creencias rcligiosas, entonces hemos de optar por la vía de la irracionalidad o, si se prefiere, de la $f e$. El fideísta asume la idea de que los contenidos de las creencias religiosas rebasan por completo las capacidades humanas de aprehensión y que, por consiguiente, no hay nada que intentar demostrar. Lo único que se puede hacer es creer (a ciegas): creer que hay un Dios, que hay salvación del alma, etc. El fideísta estaría dispuesto incluso a sostencr que es irracional exigir pruebas, verificación, corroboración de alguna índole en relación con las creencias religiosas: se sabe $a$ priori que no se nos puede dar tal cosa. El examen del tcma requiere, naturalmente, que primero se aclaren las nociones empleadas.

Aparte de la dicotomía "racionalidad-fideísmo", tal vez la distinción más útil para nosotros en este contexto sea la de "a-racionalidad-irracionalidad". Por a-racionalismo entiendo aquí la posición de acuerdo con la cual no es posible dar razones para todas nuestras decisiones, acciones, creencias, etc., sino que hay que reconocer que hay un término, un punto final en los procesos explicativos. El irracionalismo, en cambio, sería la doctrina que afirmaría que podemos pensar y actuar justificadamente de un modo que la razón condena. La pregunta que debemos entonces plantearnos ahora es: ¿es el fideísta a-racionalista o irracionalista? Y si se demuestra que el fideísta tiene que ser irracionalista ¿qué consecuencias tendría ello para el status, la naturaleza, etc., de la creencia religiosa?

$\mathrm{El}$ irracionalismo se presenta, a primera vista, como una posición teóricamente insostenible. En primer lugar, parecería que se refuta a sí mismo: el irracionalista estaría dando razones para justificar su tesis de que las razones no son necesarias. Esto no parece inteligible. En segundo lugar, lo menos que se podría esperar de un irracionalista es que estableciera alguna clase de vínculo entre los incomprensibles dogmas aceptados por fe y nuestras acciones. Con ello estaría demostrando que en 
efecto se puede actuar y pensar de modo irracional. El problema aquí es que un absurdo puede dar lugar a cualquier línea de acción (e.g., de una contradicción se sigue cualquier cosa). Pero entonces la posición irracionalista no sólo es inaceptable, sino que ni siquiera se entiende. De ahí que no sea conveniente hacer del fideíamo una corriente irracionalista. Ahora bien ¿puede el fideísta ser a-racionalista? El a-racionalismo es prima facie perfectamente inteligible. La noción de jerarquías de lenguaje ayuda a comprender el punto. Lo que el a-racionalista sostiene es que hay un nivel 1 en el que los seres humanos actúan y, en algunos casos, argumentan para justificar alguna de sus acciones; pero hay también un nivel 2 desde el cual se habla de todo lo que acontece en el nivel l; habría un nivel 3 desde el cual se podría comprender por qué no todas las creencias de nivel 2 son justificables, etc. El a-racionalista ni elogia ni propone nada: simplemente describe. $\mathrm{O}$ sea, él argumenta, con razones, por ejemplo, de grado 2 , que hay creencias o acciones de grado 1 para las cuales ya no hay razones y que es absurdo pedirlas. A diferencia de lo que sucede con el irracionalista, el a-racionalista no se contradice. Pero ipuede el fideísta asumir esta posición?

Antes de responder, quisiera señalar que parece impecable la estrategia de adaptar al caso de la creencia religiosa los resultados alcanzados por Wittgenstein en On Certainty. Desde esta perspectiva, el conocimiento humano presupone creencias que simplemente "están alli”" y que son tales que, si no nos adherimos a ellas, si no las aceptamos sin cuestionarlas, si pretendemos rechazarlas, entonces no podemos dar cuenta de absolutamente nada. Wittgenstein es, pues (claramente) un a-racionalista. De acuerdo con él, hay creencias cuya justificación ya no es otra creencia, sino la acción, la praxis. Esto, empero, es de graves consecuencias para nuestro tema.

Por lo pronto, parecería que el fideísta no puede ser un aracionalista. Este último acepta razones (de diverso nivel, según el caso), pero se esfuerza por demostrar que es ilegítimo 
exigir en un momento dado una justificación suplementaria para una creencia dada. Pero lo que él sostiene no está conectado especialmente con el contenido de las creencias, ni depende de ello. Desde este punto de vista, el a-racionalista es neutral. Yo creo que podemos incluso ir más lejos y afirmar que el a-racionalista tiene que poder comprender las creencias de que se trate para poder intentar determinar posteriormente si éstas son justificables en principio o no. Al fideísta, en cambio, esta posición le está, según todas las apariencias, vedada. Su rechazo de las justificaciones tiene que ver con su contenido, no con consideraciones de orden metodológico. Pero si esto es así, entonces habría que concluir que, en vista de que el fideísta no puede ser ni racionalista ni a-racionalista, entonces tiene que ser irracionalista. En otras palabras, lo que el fideísta sostiene o tiende a sostener es que hay creencias que por su complejidad o grandiosidad no son comprensibles para la mente humana: en esos casos (que se supone que es el de la religión) hay simplemente que aceptar las creencias de que se trate. No hay que estudiarlas, intentar comprenderlas, argumentar en su favor, etc. Lo único que hay que hacer es hacerlas suyas. El problema entonces es el siguiente: ¿es aceptable o, incluso, inteligible, la tesis de que es posible adoptar o hacer suyas creencias que no se comprenden? Dependiendo de la respuesta que estemos preparados a dar a esta pregunta estaremos en posición de asumir o rechazar cualquiera de las alternativas del par ordenado "fideísmo-racionalismo" o bien, rechazando dicha alternativa, podremos encauzar nuestros esfuerzos por el aclaratorio sendero de la filosofía wittgensteiniana de la religión.

Recibido: 13 de diciembre de 1991 . 


\section{SUMM $\Lambda$ RY}

In this paper I try to show, having recourse mainly to two Wittgenstcinian concepts (viz., critcria and family resemblances), what the conditions for ascription of religious beliefs are. I emphasize the use of religious language and religious praxis. From this perspective, the question of how is a religious belief verified changes dramatically. The point of this analysis is to make clear why to intcrpret religious beliefs (and assertions) as factual beliefs is radically misguided. This does not mean that we cannot speak at all of "religious verification", but only that 'verification' in this context must mean something quite different from what it means in, say, scientific contexts. I discuss Hick's views on "escatological verification" and Iry lo show why the concept is spureous and, accordingly, why it cannot work. Finally, I altempt to show that the impossibility of empirical verification of religious belicf commits a belicver with a rejection of classical theism but not with any kind of irralionalism. 